Research Note

\title{
Black Lives Matter for Whites' Racial Prejudice: Assessing the Role of Social Movements in Shaping Racial Attitudes in the United States
}

\author{
Soumyajit (Shom) Mazumder ${ }^{\dagger}$ \\ Harvard University \\ smazumder@g . harvard.edu
}

Date last updated: May 5, 2019

Word Count: 3890

\begin{abstract}
Black Lives Matter (BLM) is one of the most prominent contemporary social movements in the United States. Whether the BLM movement has led to racial attitude liberalization remains an open question. I evaluate this question using data on over 140,000 survey respondents combined with locational data on BLM protests in 2014 following the police killing of Michael Brown and Eric Garner. Results from a difference-in-differences identification strategy provide evidence indicating that the BLM movement was successful in reducing whites' racial prejudice. I find that these effects follow an age gradient where young whites are liberalized by protests while older whites are not. Results from this study indicate that protests can be successful drivers of attitude change.
\end{abstract}

*I thank Sean McElwee for pushing me to study this question. I would also like to thank Des King for illuminating discussions on the subject. For helpful comments on the draft, I thank Chris Chaky and Alex HertelFernandez. All errors are the author's own.

${ }^{\dagger}$ Ph.D. Candidate, Department of Government, Harvard University, web: http: //smazumder .me 


\section{INTRODUCTION}

Do protests work? This question has spawned a rich debate across political science, sociology, and economics about the efficacy of protests (Andrews 1997; McAdam and Su 2002; Chenoweth and Stephan 2012; Gillion 2012; Madestam et al. 2013; Branton et al. 2014; Wallace, Zepeda-Millan, and Jones-Correa 2014; Biggs and Andrews 2015; Huff and Kruszewska 2016; Wasow 2017; Mazumder 2018; Enos, Kaufman, and Sands, Forthcoming). While a large portion of this research focuses on the link between protests and electoral or institutional change, a growing literature has also highlighted the relationship between protests and broader attitudinal change (Collingwood, Lajevardi, and Oskooii 2018; Mazumder 2018). Particularly, an open question remains as to whether protests and social movements can generate attitudinal change in line with the goals of the protesters or if protests generate backlash against the broader cause. Given the sudden resurgence of social movements in American politics, this question is particularly relevant for understanding what role protests play in the trajectory of public opinion.

I examine this classic question within the context of the Black Lives Matter (BLM) movementone of the most prominent contemporary social movements in the United States. This wave of protests and actions by BLM is in response to the police harming and killing primarily black, unarmed civilians. The term "Black Lives Matter" first appeared on social media in response to George Zimmerman's shooting of Trayvon Martin in 2012 by black, female activists (Garza 2014). Police killings of Eric Garner and Michael Brown converted the hashtag into a national movement with a wave of protests-often days or weeks long-across the country. Following a grand jury decision to not indict the police officer who killed Eric Garner, another wave of protests exploded in the United States.

Inspired by the police killing of black, unarmed civilians like Michael Brown in Ferguson, Missouri and Eric Garner in New York City, the BLM movement seeks to highlight and overcome "...state-sanctioned violence and anti-Black racism" (Black Lives Matter 2019). Thus, a clear goal of the movement is to fundamentally shape whites attitudes toward blacks. In this research note, I seek to understand whether BLM was successful at this objection. By doing so, I also hope to shed light on the efficacy of protests in age where racial issues are highly polarizing.

To empirically evaluate the impact of BLM protests on racial attitudes, I combine survey data from 2010-2018 from the Cooperative Congressional Election Study (CCES) on whites $(N>140,000)$ with geolocated data on the counties exposed to BLM protests in 2014 (the year of the Eric Garner and Michael Brown protests). ${ }^{1}$ A key advantage of this dataset is that the large sample size allows for making inferences with respect to fine-grained geographic units like counties in addition to having the racial resentment battery asked consistently over time to facilitate over time comparisons. Using a difference-in-differences identification strategy comparing whites from counties with protests before and after 2014 to whites in counties without protests before and after 2014, I find evidence that whites became less racially resentful

\footnotetext{
${ }^{1}$ I use 2014 since this was the first major wave of protests by BLM. While there were protests after 2014, these were likely affected by the the first-wave thus rendering these treated units tenuous for making causal inferences.
} 
toward blacks in response to BLM protests. The magnitude of the effect, though, is substantively moderate with individuals exposed to protest counties reducing their racial resentment by approximately one tenth of a standard deviation. Results investigating heterogeneity of the effect indicate that an age gradient exists. Among individuals younger than 50, BLM protests reduced racial resentment while there is a slight positive effect among individuals older than 50 highlighting the relevance of the age divide in American politics. A number of robustness checks including controlling for a key determinant of protests-the presence of police killings of unarmed civilians-as well as controlling for differential trends by cities help to bolster the causal interpretation of the findings. Overall, the results suggest that protests do work on average, but with the caveat that this response is not uniform by age.

These results contribute to two key literatures in political science. First, this note adds to a growing set of evidence across a number of historical contexts that protests-even violent ones-can actually achieve their goals in changing attitudes and behavior (Mazumder 2018; Enos, Kaufman, and Sands, Forthcoming). One particular worry with the existing studies is that either the Civil Rights Movement (Mazumder 2018) or the L.A. Riots (Enos, Kaufman, and Sands, Forthcoming) might be very unique with respect to the universe of protests. This study shows that protests still are successful in changing attitudes and behavior even in another more modern context. This study is also the first, to my knowledge, to evaluate the direct impact of BLM on racial attitudes. While other studies of the BLM movement in political science tend to focus on its causes (Williamson, Trump, and Einstein 2018), I show that it also has political consequences in terms of public opinion change.

Second, this note adds to the literature on the importance of critical events or junctures in shaping racial attitudes in the United States (Sears and Valentino 1997; Pierson 2000). One major strand of work in American politics focuses on the Civil Rights Movement in catalyzing the partisan, racial realignment of partisan identification (Valentino and Sears 2005; Kuziemko and Washington 108). At the same time, the Civil Rights Movement also generated a broader elite backlash that laid the groundwork for the carceral state (Weaver 2007). This paper joins this literature in highlighting the key role that social movements play in the inflection point of the American racial order (King and Smith 2005).

The rest of the research note proceeds as follows. First, I describe the data used to evaluate the impact of protests on racial attitudes. Then, I outline the research design used to establish a causal relationship between protests and racial attitudes. Next, I present the results of this analysis and investigate effect heterogeneity. I conclude by discussing the implications of these results for American politics as well as highlighting unexplored, but relevant questions stemming from the findings.

\section{RESEARCH DESIGN AND RESULTS}

In this section, I assemble data from the 2010, 2012, 2014, and 2018 rounds of the CCES to study the impact of BLM protests on racial attitudes. ${ }^{2}$ I describe a difference-in-differences

\footnotetext{
${ }^{2}$ Unfortunately, I am forced to drop 2016 since the CCES did not ask the racial resentment battery.
} 
(DID) identification strategy to rule out time-invariant confounders and show that protests seem to have reduced racial resentment among whites.

\section{Data}

To measure racial attitudes, I rely on repeated rounds of the CCES from 2010-2018 (excluding 2016) from the racial resentment battery-a standard set of questions used to measure racial prejudice. $^{3}$ These questions ask respondents to indicate whether they agree or disagree with the following statements: (1) "Irish, Italians, Jewish and many other minorities overcame prejudice and worked their way up. Blacks should do the same without any special favors." and (2) "Generations of slavery and discrimination have created conditions that make it difficult for blacks to work their way out of the lower class." I rescale answers to these questions from one to five such that higher values indicate greater racial resentment toward blacks. The final racial resentment outcome takes the average of each individual item since this reduces measurement error in responses (Ansolabehere, Rodden, and Snyder Jr. 2008). I restrict the sample to only consider whites since these are the individuals for whom this battery has construct validity.

To measure BLM protests, I scraped data on the location of BLM protests from Alisa Robinson hosted on https://elephrame.com/textbook/BLM/chart. After geolocating each event to their respective counties, I subset the data to protests that happened in 2014 which coincides with the Eric Garner and Michael Brown waves of BLM protests. Finally, I remove events located on university campuses though this does not substantively effect the results.

\section{Identification Strategy}

The key empirical concern in ascertaining the impact of BLM protests on racial attitudes is that selection of places that receive protests might be driven by existing unobserved factors. On one hand it might be the case that areas that experience protests might be the most racially conservative ones or the areas most prone to police violence against blacks (Williamson, Trump, and Einstein 2018). On the other hand, protests require tapping into existing activist bases, which might come from places that are already more racially liberal. Thus, simply comparing the difference in racial attitudes between individuals residing in protest versus non-protest counties would lead to misleading inferences about the causal effect of BLM protests.

To address this issue, I leverage a DID design which compares changes in racial attitudes pre and post-protest differentially by protest and non-protest counties. Essentially, this strategy uses the pre-period trend of counties that never received protests as a counterfactual trend for the protest counties had they never had protests. This strategy, then, eliminates time invariant factors at the county-level such as the ones described above. The key assumption for this analysis is that there is no time-varying confounding also known as parallel trends. I visually

\footnotetext{
${ }^{3}$ There is some debate as to whether racial resentment meaningfully measures anti-black attitudes or just general conservatism or out-group prejudice (Sniderman and Tetlock 1986; Sears and Henry 2003; Carney and Enos 2018). For the purposes of this paper, I use the racial resentment questions since they are the best available measures of racial attitudes asked consistently over time.
} 


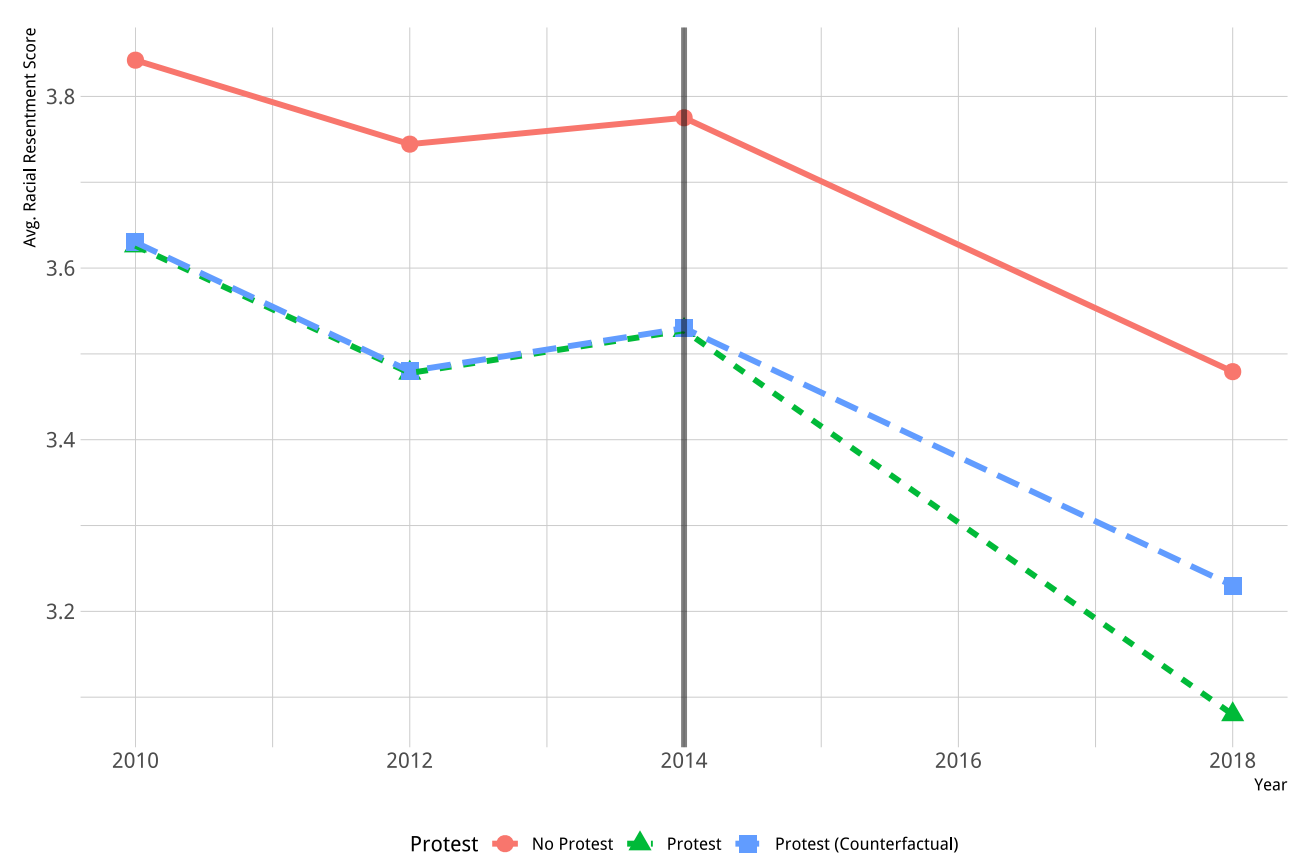

Figure 1: Parallel Trends Plot

assess this in Figure 1 by plotting the average racial resentment score over time by treatment status. This analysis shows support for the assumption needed for causal identification within a DID framework.

Given this assumption, I estimate the following equation using Weighted Least Squares weighted by the CCES survey weights: ${ }^{4}$

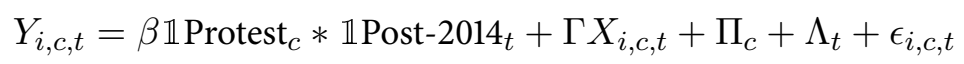

Here, the outcome $Y_{i, c, t}$ is the average racial resentment score for an individual $i$ in county $c$ in year $t$. The key causal parameter of interest is $\beta$, which represents the Average Treatment Effect among the Treated (ATT) of protests on racial resentment. I also have models that include individual-level covariates such as age and gender (interacted). The term $\Pi$ capture county-level fixed effects making all comparisons within county. I also include fixed effects for year $\Lambda$ to flexibly control for overall time trends in racial resentment. The term $\epsilon_{i, c, t}$ represents an individual-level error term. For inference, I cluster standard errors at the county level $c$ since this is the unit where the treatment is assigned.

\footnotetext{
${ }^{4}$ The results are robust to using Ordinary Least Squares without survey weights as well.
} 
Results

Table 1: Main DID Results among Whites

\begin{tabular}{lcc}
\hline & \multicolumn{2}{c}{ Racial Resentment Index } \\
& $(1)$ & $(2)$ \\
\hline Protest ${ }^{*}$ Post-2014 & $-0.146^{* * *}$ & $-0.139^{* * *}$ \\
& $(0.034)$ & $(0.033)$ \\
Survey Weights & Yes & Yes \\
County FE & Yes & Yes \\
Year FE & Yes & Yes \\
Individual Ctrls & No & Yes \\
Ctrl Grp Mean & 3.713 & 3.713 \\
$\mathrm{~N}$ & 148,401 & 148,401 \\
\hline${ }^{*} \mathrm{p}<.1 ;{ }^{* *} \mathrm{p}<.05 ;{ }^{* * *} \mathrm{p}<.01$ &
\end{tabular}

Table 1 presents the results from the DID design. White respondents exposed to BLM protests have a reduction in racial resentment by about 0.14 points. This impact is statistically significant at the $p<0.001$ level and the magnitude of the effect is stable with and without individual level controls for age and gender as well as their interaction. In substantive terms, this represents about a 0.11 standard deviation decrease in racial resentment. This effect is essentially on par with recent work that looks at the legacy of slavery on racial attitudes (Acharya, Blackwell, and Sen 2018), which finds that “...a 20 percentage-point increase in the slave proportion (roughly a one standard-deviation change)...0.08 point increase in the average racial resentment score in the county." Benchmarking the effect against the raw difference between Democrats and Republicans, the estimated effect would close the gap by about $10 \%$. Given the marked stability of racial attitudes, which are often times the product of historical forces and early socialization, these effects are substantively meaningful.

While on average it seems as if protests are reducing racial prejudice among whites, this might mask interesting forms of heterogeneity. Importantly, recent work highlights the role of the age divide in American politics where racial liberalism might be driven by younger rather than older Americans. ${ }^{5}$ I investigate whether this feature manifests itself with respect to the impact of protests by analyzing the effect of BLM protests across the distribution of ages in the sample. Figure 2 plots both the coefficient from a regression model as well as the binned estimates as suggested by Hainmueller, Mummolo, and Xu (2019) to relax the linearity assumption. From this, a striking pattern emerges: protests seem to decrease prejudice among those who are younger than 50. For those older than 50, there is some evidence a backlash whereby older whites are becoming more conservative in response to BLM protests with re-

\footnotetext{
${ }^{5}$ I also investigate heterogeneity between college graduates and non-graduates. I find little evidence of a heterogeneous effect (see Supplementary Appendix).
} 


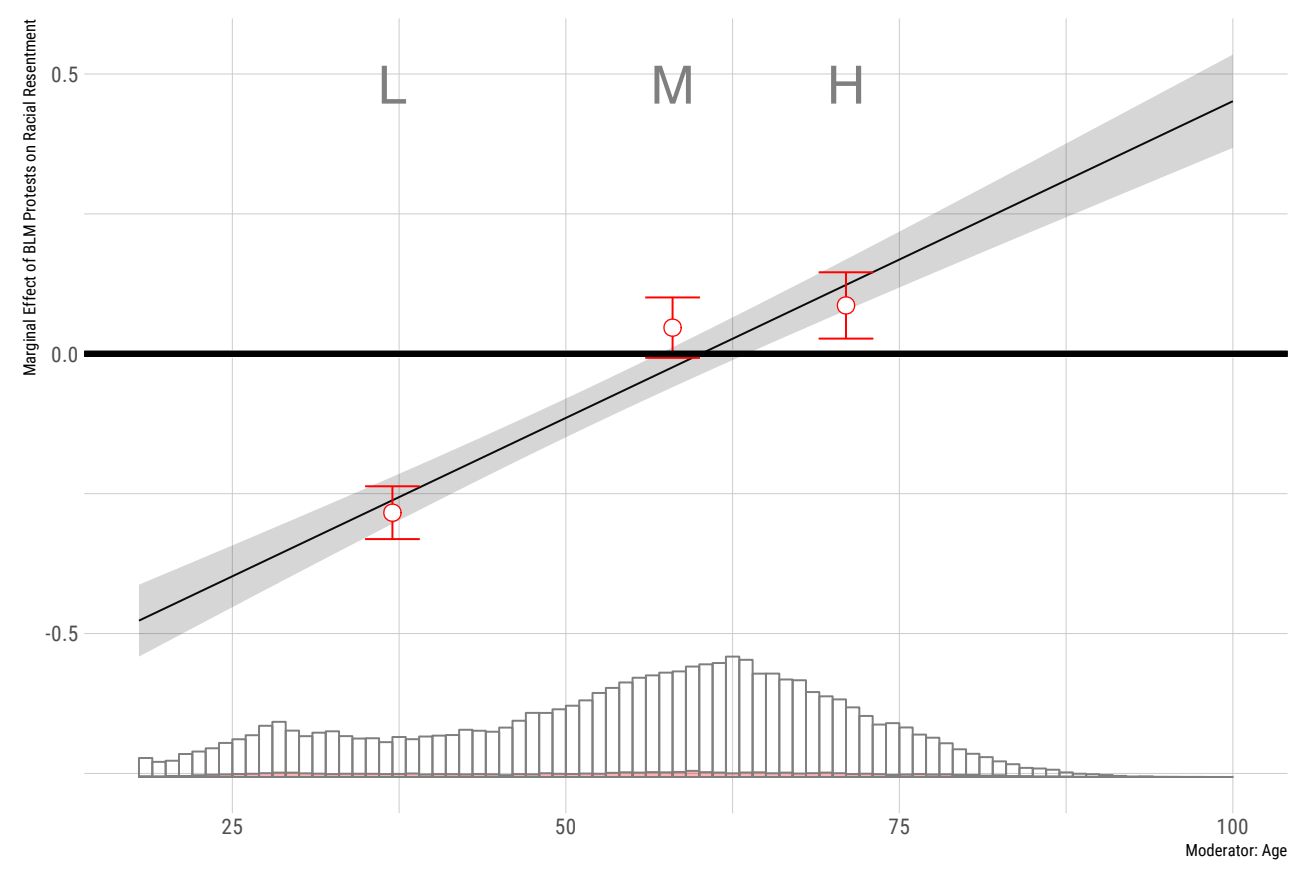

Figure 2: Heterogeneity by Age

spect to racial attitudes suggesting that BLM protests polarized the American electorate across the age divide. These results are also consistent with the socialization literature, which argues that individuals are more likely to change their attitudes younger in life (Sears and Valentino 1997). ${ }^{6}$

To probe the validity of the results, I run a number of robustness checks (see Supplementary Appendix). To assuage concerns about the weighting scheme and samples, I also re-run the models without survey weights and the results are similar. In addition, I also show that the results hold when looking at all respondents, though the magnitude of the effect diminishes somewhat. I also run a permutation test where I randomly permute the treated counties and re-estimate the model. I show that the observed effect is significantly different than the distribution of effects under the null of no treatment effect. I also run models controlling for police killings of unarmed civilians and the results hold. In addition, I also control for differential trends by urbanization and find that the results are not driven by cities simply becoming more liberal over time. Moreover, I also estimate models controlling for differential trends across

${ }^{6}$ While partisanship is clearly an important force in American politics, I do not investigate heterogeneity by partisanship since this is a post-treatment outcome, which would break the causal interpretation of the results. Results in the Supplementary Appendix indicate that protests did indeed increase whites' party identification with Democrats. 
states and the point estimates remain unchanged. Together, these results bolster the finding that BLM protests reduced racial prejudice in the American public.

\section{CONCLUSION}

Do protests work? I investigate this question within the context of the BLM movement using data on racial attitudes from large-scale public opinion surveys. Using a DID strategy to eliminate time-invariant confounders, I find that BLM protests reduced racial prejudice among whites as measured by racial resentment. These results are substantively meaningful and compare to recent results on the deep legacies of political institutions. Moreover, I find that the results are particularly strong for younger individuals in addition some evidence of backlash by older whites.

These results contribute to a burgeoning set of research which seeks to understand whether protests work to achieve the goals of the protesters. While some existing research examines the case of BLM, the research designs only compare overall changes in attitudes over time instead of using counties without any protests to generate more plausible counterfactual comparisons (Sawyer and Gampa 2018). This paper, using more rigorous causal inference strategies like DID, finds that BLM was successful in shifting public opinion toward becoming more racially liberal. That BLM actually is able to shift white public opinion to become more racially liberal is actually quite surprising given the movements reliance on adversarial tactics suggesting that tactics per se might not hinder social movements in certain settings (Chenoweth and Stephan 2012; Huff and Kruszewska 2016; Wasow 2017; Enos, Kaufman, and Sands, Forthcoming).

Given the centrality of policing and state-violence in the lives of people of color and the poor (Soss and Weaver 2017), a large strand of literature shows that these types of experiences often times have demobilizing impacts in terms of traditional forms of political participation like voting (Weaver and Lerman 2010; White 2019). In response, protests and social movements have emerged as forms of political resistance and participation from below much like during the Civil Rights Movement (Williamson, Trump, and Einstein 2018). With the importance of policing for the lives of these communities and the way in which protest forms a way to engage in a political system that lacks a sense of democracy in the eyes of those affected (Eckhouse 2018), it is important to better understand what protest can and cannot achieve. While this research note shoes that BLM was able to change whites' racial attitudes, it remains an open question as to how BLM has shaped local, state, and national institutions. Moreover, it is also important to understand under what conditions movements like BLM can achieve their goals in a way that remains durable. The hope is that this note catalyzes future research into the possibilities and limits of protest in a polarized age. 


\section{References}

Acharya, Avidit, Matthew Blackwell, and Maya Sen. 2018. Deep Roots: How Slavery Still Shapes Southern Politics. Princeton University Press.

Andrews, Kenneth T. 1997. "The Impacts of Social Movements on the Political Process: The Civil Rights Movement and Black Electoral Politics in Mississippi." American Sociological Review 62 (5): 800-819.

Ansolabehere, Stephen, Jonathan Rodden, and James M Snyder Jr. 2008. “The Strength of Issues: Using Multiple Measures to Gauge Preference Stability, Ideological Constraint, and Issue Voting." American Political Science Review 102 (2): 215-232.

Biggs, Michael, and Kenneth T. Andrews. 2015. "Protest Campaigns and Movement Success: Desegregating the U.S. South in the Early 1960s." American Sociological Review 80 (2): 416443.

Branton, Regina, et al. 2014. "Social Protest and Policy Attitudes: The Case of the 2006 Immigrant Rallies.” American Journal of Political Science 59 (2): 390-402.

Carney, Riley K., and Ryan D. Enos. 2018. "Conservatism and Fairness in Contemporary Politics: Unpacking the Psychological Underpinnings of Modern Racism.” Working Paper.

Chenoweth, Erica, and Maria J Stephan. 2012. Why Civil Resistance Works: The Strategic Logic of Nonviolent Conflict. Columbia University Press.

Collingwood, Loren, Nazita Lajevardi, and Kassra A.R. Oskooii. 2018. "A Change of Heart? Why Individual-Level Public Opinion Shifted Against Trump's 'Muslim Ban'” Political Behavior.

Eckhouse, Laurel. 2018. "White Riot: Race, Institutions, and the 2016 U.S. Election.” Politics, Groups, and Identities.

Enos, Ryan D., Aaron Russell Kaufman, and Melissa L. Sands. Forthcoming. "Can Violent Protest Change Local Policy Support? Evidence from the Aftermath of the 1992 Los Angeles Riot." American Political Science Review.

Garza, Alicia. 2014. "A Herstory of the BlackLivesMatter Movement." The Feminist Wire.

Gillion, Daniel Q. 2012. "Protest and Congressional Behavior: Assessing Racial and Ethnic Minority Protests in the District." The Journal of Politics 74 (4): 950-962. 
Hainmueller, Jens, Jonathan Mummolo, and Yiqing Xu. 2019. “How Much Should We Trust Estimates from Multiplicative Interaction Models? Simple Tools to Improve Empirical Practice." Political Analysis 27 (2): 163-192.

Huff, Connor, and Dominika Kruszewska. 2016. "Banners, Baricades, and Bombs: The Tactical Choices of Social Movements and Public Opinion." Comparative Political Studies 49 (13): 1774-1808.

King, Desmond S, and Rogers M Smith. 2005. "Racial Orders in American Political Development." American Political Science Review 99 (1): 75-92.

Kuziemko, Ilyana, and Ebonya Washington. 108. "Why Did the Democrats Lose the South? Bringing New Data to an Old Debate." American Economic Review 10 (2830-2867).

Madestam, Andreas, et al. 2013. "Do Political Protests Matter? Evidence from the Tea Party Movement." Quarterly Journal of Economics 128 (4): 1633-1685.

Mazumder, Soumyajit. 2018. “The Persistent Effect of the U.S. Civil Rights Movement on Political Attitudes." American Journal of Political Science 62 (4): 922-935.

McAdam, Doug, and Yang Su. 2002. "The War at Home: The Impact of Anti-War Protests, 1965-1973.” American Sociological Review 67:696-721.

Pierson, Paul. 2000. “Increasing Returns, Path Dependence, and the Study of Politics." American Political Science Review 94 (2): 251-267.

Sawyer, Jeremy, and Anup Gampa. 2018. "Implicit and Explicit Racial Attitudes Changed During Black Lives Matter." Personality and Social Psychology Bulletin 44 (7): 1039-1059.

Sears, David O., and P.J. Henry. 2003. "The Origins of Symbolic Racism." Journal of Personality and Social Psychology 85 (3): 259-275.

Sears, David O., and Nicholas A. Valentino. 1997. "Politics Matters: Political Events as Catalysts for Preadult Socialization." American Political Science Review 91 (1): 45-65.

Sniderman, Paul M., and Philip E. Tetlock. 1986. "Symbolic Racism: Problems of Motive Attribution in Political Analysis." Journal of Social Issues 42 (2): 129-150.

Soss, Joe, and Vesla Weaver. 2017. "Police Are Our Government: Politics, Political Science, and the Policing of Race-Class Subjugated Communities." Annual Review of Political Science 20:565-591.

Valentino, Nicholas A., and David O. Sears. 2005. "Old Times There Are Not Forgotten: Race and Partisan Realignment in the Contemporary South." American Journal of Political Science 49 (3): 672-688.

Wallace, Sophia J, Chris Zepeda-Millan, and Michael Jones-Correa. 2014. "Spatial and Temporal Proximity: Examining the Effects of Protests on Political Attitudes." American Journal of Political Science 58 (2): 433-448.

Wasow, Omar. 2017. “Do Protests Matter? Evidence from the 1960s Black Insurgency." Working Paper. \%5Curl\%7Bhttp: //www.omarwasow. com/Protests_on_Voting.pdf\%7D. 
Weaver, Vesla M. 2007. "Frontlash: Race and the Development of Punitive Crime Policy." Studies in American Political Development 21 (2): 230-265.

Weaver, Vesla M, and Amy E Lerman. 2010. "Political Consequences of the Carceral State." American Political Science Review 104 (4): 817-833.

White, Ariel. 2019. "Misdemeanor Disenfranchisement? The Demobilizing Effects of Brief Jail Spells on Potential Voters." American Political Science Review.

Williamson, Vanessa, Kris-Stella Trump, and Katherine Levine Einstein. 2018. "Black Lives Matter: Evidence that Police-Caused Deaths Predict Protest Activity." Perspectives on Politics 16 (2): 400-415. 


\section{SUPPLEMENTARY APPENDIX}

Protest Locations across U.S. Counties in 2014

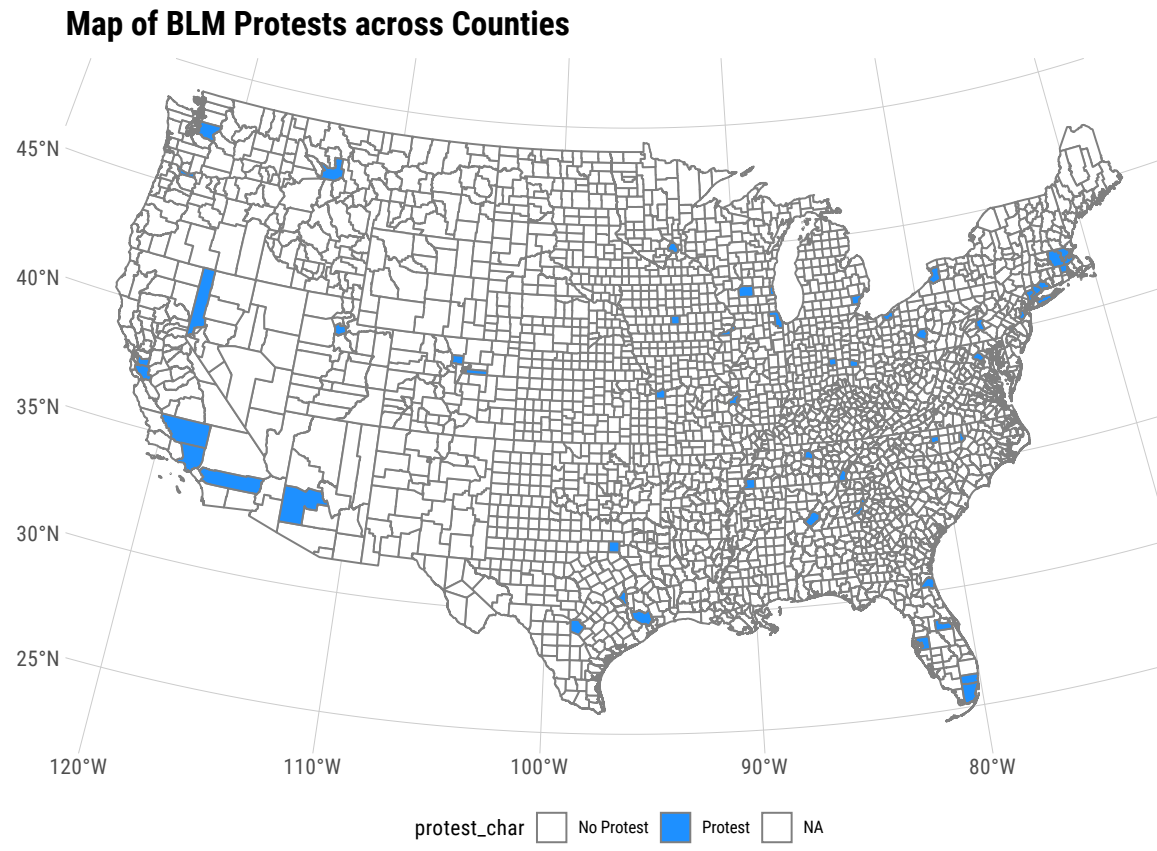

Figure A1-1: 
DID Results among Whites (Unweighted)

Table A1-1: Main DID Results among Whites

\begin{tabular}{lcc}
\hline & \multicolumn{2}{c}{ Racial Resentment Index } \\
& $(1)$ & $(2)$ \\
\hline Protest $^{*}$ Post-2014 & $-0.094^{* * *}$ & $-0.092^{* * *}$ \\
& $(0.025)$ & $(0.024)$ \\
Survey Weights & No & No \\
County FE & Yes & Yes \\
Year FE & Yes & Yes \\
Individual Ctrls & No & Yes \\
Ctrl Grp Mean & 3.644 & 3.644 \\
$\mathrm{~N}$ & 148,401 & 148,401 \\
\hline${ }^{*} \mathrm{p}<.1 ;{ }^{* *} \mathrm{p}<.05 ;{ }^{* * *} \mathrm{p}<.01$ &
\end{tabular}


DID Results among All Respondents (Weighted)

Table A1-2: Main DID Results among All Respondents

\begin{tabular}{lcc}
\hline & \multicolumn{2}{c}{ Racial Resentment Index } \\
& $(1)$ & $(2)$ \\
\hline Protest*Post-2014 & $-0.061^{* * *}$ & $-0.040^{*}$ \\
& $(0.023)$ & $(0.022)$ \\
Survey Weights & Yes & Yes \\
County FE & Yes & Yes \\
Year FE & Yes & Yes \\
Individual Ctrls & No & Yes \\
Ctrl Grp Mean & 3.567 & 3.567 \\
$\mathrm{~N}$ & 191,566 & 191,566 \\
\hline${ }^{*} \mathrm{p}<.1 ;{ }^{* *} \mathrm{p}<.05 ;{ }^{* * *} \mathrm{p}<.01$ & \\
\end{tabular}


DID Results among All Respondents (Unweighted)

Table A1-3: Main DID Results among All Respondents

\begin{tabular}{lcc}
\hline & \multicolumn{2}{c}{ Racial Resentment Index } \\
& $(1)$ & $(2)$ \\
\hline Protest ${ }^{*}$ Post-2014 & $-0.035^{* *}$ & $-0.028^{*}$ \\
& $(0.017)$ & $(0.016)$ \\
Survey Weights & No & No \\
County FE & Yes & Yes \\
Year FE & Yes & Yes \\
Individual Ctrls & No & Yes \\
Ctrl Grp Mean & 3.517 & 3.517 \\
$\mathrm{~N}$ & 191,566 & 191,566 \\
\hline$*$
\end{tabular}

${ }^{*} \mathrm{p}<.1 ;{ }^{* *} \mathrm{p}<.05 ;{ }^{* * *} \mathrm{p}<.01$ 
Permutation Test of Sharp Null

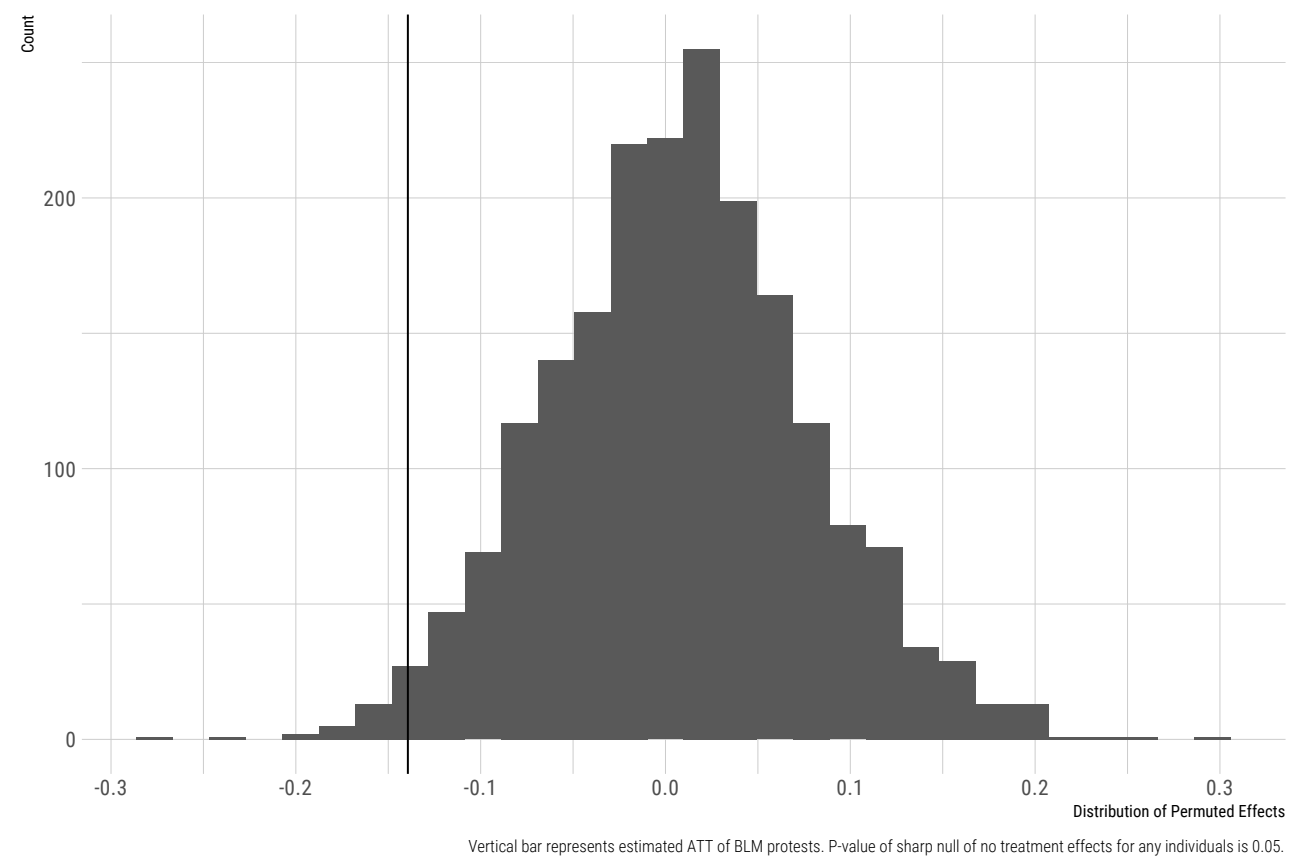

Figure A1-2: Randomization Distribution under the Null 
Robustness to Controlling for Police Killings

Table A1-4: Main DID Results among Whites

\begin{tabular}{lcc}
\hline & \multicolumn{2}{c}{ Racial Resentment Index } \\
& $(1)$ & $(2)$ \\
\hline Police Killing ${ }^{*}$ Post-2014 & $-0.068^{* * *}$ & $-0.071^{* * *}$ \\
& $(0.021)$ & $(0.021)$ \\
Protest ${ }^{*}$ Post-2014 & $-0.124^{* * *}$ & $-0.117^{* * *}$ \\
& $(0.035)$ & $(0.034)$ \\
Survey Weights & Yes & Yes \\
County FE & Yes & Yes \\
Year FE & Yes & Yes \\
Individual Ctrls & No & Yes \\
Ctrl Grp Mean & 3.713 & 3.713 \\
$\mathrm{~N}$ & 148,401 & 148,401 \\
\hline${ }^{*} \mathrm{p}<.1 ;{ }^{* *} \mathrm{p}<.05 ;{ }^{* * *} \mathrm{p}<.01$ &
\end{tabular}


Robustness to Controlling for Population Density

Table A1-5: Main DID Results among Whites

\begin{tabular}{lcc}
\hline & \multicolumn{2}{c}{ Racial Resentment Index } \\
& $(1)$ & $(2)$ \\
\hline Pop. Density ${ }^{*}$ Post-2014 & -0.00001 & -0.00001 \\
& $(0.00000)$ & $(0.00000)$ \\
Protest ${ }^{*}$ Post-2014 & $-0.129^{* * *}$ & $-0.123^{* * *}$ \\
& $(0.036)$ & $(0.035)$ \\
Survey Weights & Yes & Yes \\
County FE & Yes & Yes \\
Year FE & Yes & Yes \\
Individual Ctrls & No & Yes \\
Ctrl Grp Mean & 3.713 & 3.713 \\
$\mathrm{~N}$ & 148,401 & 148,401 \\
\hline${ }^{*} \mathrm{p}<.1 ;{ }^{* *} \mathrm{p}<.05 ;{ }^{* * *} \mathrm{p}<.01$ &
\end{tabular}


Robustness to State by Year FE

Table A1-6: DID Results among Whites (State by Year FE)

\begin{tabular}{lcc}
\hline & \multicolumn{3}{c}{ Racial Resentment Index } \\
& $(1)$ & $(2)$ \\
\hline Protest*Post-2014 & $-0.131^{* * *}$ & $-0.125^{* * *}$ \\
& $(0.029)$ & $(0.029)$ \\
Survey Weights & Yes & Yes \\
County FE & Yes & Yes \\
Year FE & Yes & Yes \\
Individual Ctrls & No & Yes \\
State by Year FE & Yes & Yes \\
Ctrl Grp Mean & 3.713 & 3.713 \\
$\mathrm{~N}$ & 148,401 & 148,401 \\
\hline${ }^{*} \mathrm{p}<.1 ;{ }^{* *} \mathrm{p}<.05 ;{ }^{* * *} \mathrm{p}<.01$ &
\end{tabular}




\section{Heterogeneity by Education}

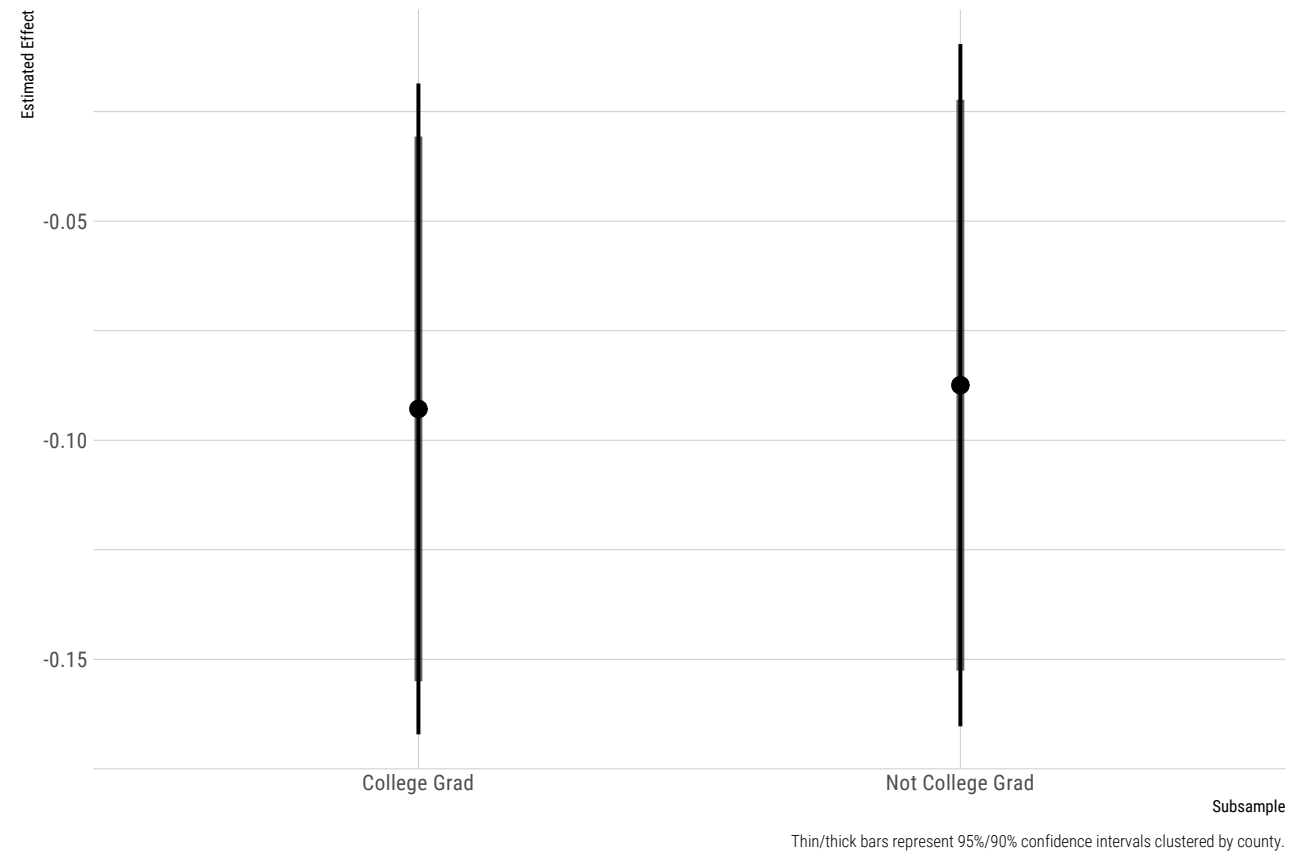

Figure A1-3: Heterogeneity by Education 
Effect on Party Identification

Table A1-7: Main DID Results among Whites

\begin{tabular}{lcc}
\hline & \multicolumn{2}{c}{ PID $=$ Democrat } \\
& $(1)$ & $(2)$ \\
\hline Protest ${ }^{*}$ Post-2014 & $0.039^{* * *}$ & $0.040^{* * *}$ \\
& $(0.010)$ & $(0.010)$ \\
Survey Weights & Yes & Yes \\
County FE & Yes & Yes \\
Year FE & Yes & Yes \\
Individual Ctrls & No & Yes \\
Ctrl Grp Mean & 0.259 & 0.259 \\
$\mathrm{~N}$ & 154,242 & 154,242 \\
\hline${ }^{*} \mathrm{p}<.1 ;{ }^{* *} \mathrm{p}<.05 ;{ }^{* * *} \mathrm{p}<.01$ & \\
& &
\end{tabular}

